\title{
Long-Term Behavior of RC Beams Strengthened with Hybrid Composite Beam
}

\author{
IL-Heon Kim ${ }^{1}$, Hyung-Joo Lee ${ }^{1}$, Joo-Won Kang ${ }^{2}$ and Yeol Choi ${ }^{1, *}$ \\ 1 School of Architecture, Kyungpook National University, Daegu, 41566, Korea; kih328@knu.ac.kr (I.-H.K.); \\ Ihj3253@gyo6.net (H.-J.L.) \\ 2 School of Architecture, Yeung Nam University, Gyeongsan 38541, Korea; kangj@ynu.ac.kr \\ * Correspondence: choiyeol@knu.ac.kr; Tel.: +82-53-950-5592
}

Received: 20 February 2019; Accepted: 23 April 2019; Published: 26 April 2019

\begin{abstract}
This paper describes the results of long-term tests on reinforced concrete (RC) beams strengthened with hybrid composite beam (HCB) under two different sustained loads. Test specimens were fabricated to reflect the most common RC beam size used in school buildings in South Korea. The specimens had dimensions of $400 \mathrm{~mm}$ (width) $\times 600 \mathrm{~mm}$ (depth) $\times 6000 \mathrm{~mm}$ (length), and were tested with or without external strengthening by a hybrid composite beam (HCB). Test results showed that strengthening the $\mathrm{RC}$ beams with $\mathrm{HCB}$ not only reduced the instantaneous deflection but was also effective in decreasing long-term deflection. In this study, time-dependent factors were investigated using a modified version of the American Concrete Institute (ACI) equation. Time-dependent factors of HCB-strengthened RC beams found in the present work differed from those of other investigations due to various experimental conditions. In the present study, we found that the ACI equation may not provide a reasonable estimation of the long-term behavior of HCB-strengthened RC beams.
\end{abstract}

Keywords: hybrid composite beam; long-term behavior; time-dependent factor; RC beam; strengthening

\section{Introduction}

Since seismic records were first collected in South Korea in 1978, two powerful earthquakes of 5.1 and 5.8 magnitude were recorded in the country, without significant human injuries or serious damage to building structures in the past three years. They were the strongest earthquakes in the country so far, respectively. After that, there were big concerns about existing reinforced concrete school buildings that did not meet current seismic design codes. According to the data, more than $50 \%$ of school buildings in South Korea did not meet current seismic design codes. Thereafter, governments have conducted various strengthening works on school reinforced concrete $(\mathrm{RC})$ buildings to make them stronger so that they can withstand more powerful earthquakes, by increasing the strength of rigid structures. Many different ways for strengthening existing school buildings were used, such as damping systems, bracing, external strengthening of steel plates or fiber reinforced polymer ( FRP) composites, section enlargement and a combination of several systems [1-4]. At this time, a comprehensive understanding of the long-term behavior of FRP-strengthened RC members may be needed for analysis and developing further FRP strengthening systems in this country. Generally, the long-term behavior of structural members can be defined as a creep strain, and this creep strain is indicated as a function of time. It was found that there are several similar analytical and experimental investigations involving long-term tests of FRP-strengthened RC beams [5-9].

Chami et al. [10] reported on the creep behavior of carbon fiber reinforced polymer (CFRP)-strengthened reinforced concrete beams from a series of experiments with twenty-six RC beams with and without bonded CFRP laminates. Different reinforcement ratios were used to evaluate 
the contribution of the external reinforcement on the creep resistance of the beams. High levels of sustained load were used in order to determine the maximum sustained load that can be applied without any risk of creep failure. The applied sustained loads varied from $59 \%$ to $78 \%$ of the ultimate static capacities of the unstrengthened beams. This was done to account for the fact that strengthening is typically required when a structure is expected to carry increased service loads. It was found that CFRP-strengthening on RC beams is effective for increasing the ultimate capacities of the beams. However, test results showed there was no improvement with regard to the long-term deflections due to the addition of a very small area of CFRP compared to the tension steel reinforcement.

Arockiasamy et al. [11] investigated the time-dependent deformations of concrete beams reinforced with CFRP bars from four rectangular concrete beams, under four different uniform sustained loadings for nearly two years. Four rectangular concrete beams reinforced with CFRP bars were cast in two sizes: $152 \mathrm{~mm} \times 203 \mathrm{~mm} \times 2438 \mathrm{~mm}$; $152 \mathrm{~mm} \times 152 \mathrm{~mm} \times 2438 \mathrm{~mm}$. The beams were instrumented and monitored to observe the changes in behavior due to creep and shrinkage of concrete. Test results showed that time-dependent deflection, strain and curvature increased with the increase in the applied moment in the beams, and the rate of increase in strains and deflections was higher in the initial period of loading and tended to reduce with time under sustained loading. In this investigation, the age-adjusted elastic modulus method appears to be realistic in predicting the long-term behavior of concrete beams reinforced with CFRP. The time-dependent deflections are computed using a simple modified equation in terms of loading duration and compression CFRP reinforcement ratio. The proposed time-dependent factor due to reinforcing CFRP bars for 3, 6, 12, and 60 months showed slightly lower figures than those suggested by ACI for reinforced concrete beams.

Sobuz et al. [12] reported on the deflection and cracking behavior of $R C$ beams externally reinforced with CFRP laminates from different degrees of strengthening schemes and two types of sustained loads up to 180 days. A total of eight RC beams were cast and tested under sustained loads for cracked and un-cracked sections. It was found that attachment of a CFRP sheet can reduce the instantaneous deflection and be effective in controlling the long-term deflection. The effectiveness of CFRP-strengthened RC beams in reducing time-dependent deflections is not to the same extent as in providing flexural strength, especially for beams subjected to sustained loads lower than the service load levels. Test results showed that the larger the CFRP reinforcement ratio was, the smaller the long-term deflection. For the same sustained loading, a maximum reduction of $35 \%$ in deflection was found in uncracked three-layer strengthened beams compared to the control specimen. For the cracked section, the corresponding reduction in deflection was $56 \%$ as compared to the unstrengthened beam.

Diab et al. [13] presented the long-term deflections of beams strengthened by prestressed and non-prestressed FRP sheets. The age-adjusted effective modulus method (EMM) is used to model the creep behavior in concrete and the relaxation in FRP prestressing sheets. A tension-stiffening model was also presented to evaluate the stiffness of the cracked section. The analytical values were compared to the results obtained from a finite element code and to the experimental results from some existing papers. It was found that the analytical method proposed in this work had a good agreement with finite element methods.

From reviewing similar investigations, we knew that the majority of previous long-term tests on RC beams with FRP strengthening were conducted with relatively small or scaled-down member size [14-16]. In general, use of scaled-down tests in engineering is the most preferred method when test environments are difficult or involve complex conditions such as requiring a faster time to set up or cost-effective testing. However, there is a concern that a scaled-down test does not fully represent the same testing value as a full- or large-sized test. Therefore, results from large-scale tests are strongly preferred for better analysis and applications. In the present study, test specimens were considered to be the typical size of RC beams in school buildings used in South Korea. In addition, the long-term behavior of FRP-strengthened RC beams with relatively large-scale members has not been investigated. The experimental work in this study was done to provide more realistic data in the field of FRP applications on the strengthening or repair of RC structural members. 


\section{Experimental Program}

In general, long-term tests are not easy to conduct accurately because executing mass loading and test setup processes is somewhat complex and tedious throughout the test period. The experimental work in this paper was performed in order to understand the effect of externally strengthened hybrid composite beams (HCBs) on full-size existing RC beams that do not satisfy the current design codes. The used RC beams of $6000 \mathrm{~mm}$ in length and $400 \mathrm{~mm} \times 600 \mathrm{~mm}$ in cross section represented the typical size used in school buildings in South Korea.

\subsection{Materials}

The following materials were used in this study: type I/II Portland cement which meets the Korean standards KS L5201, 19 mm maximum size of crushed coarse aggregate with a specific gravity of 2.64, and natural sand with a specific gravity of 2.56 and a fineness modulus of 2.42 . The designed mix of concrete was prepared with the following: ordinary Portland type I/II cement $410 \mathrm{~kg} / \mathrm{m}^{3}$, aggregate $1629 \mathrm{~kg} / \mathrm{m}^{3}$, and a water-cement ratio of 0.48 . The mix proportions used were intended to have a normal weight and a target average compressive strength of $21 \mathrm{MPa}$ at 28 days, respectively [17]. For the strengthening of RC beams, a commercially available hybrid composite beam (HCB), as shown in Figure 1, was used. Table 1 shows the mechanical properties of the hybrid composite beams provided by the manufacturer. The hybrid composite beam had dimensions of $260 \mathrm{~mm}(\mathrm{~W}) \times 40 \mathrm{~mm}(\mathrm{H})$.

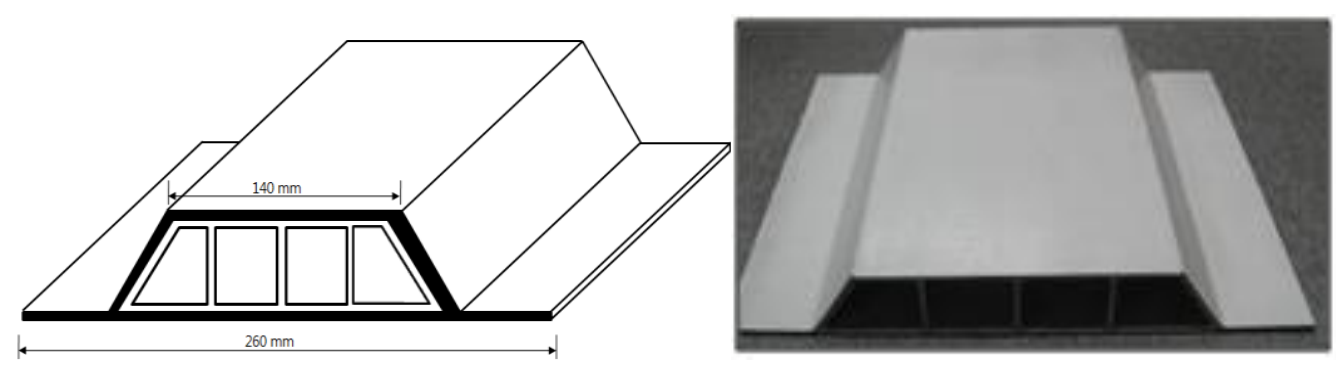

Figure 1. The hybrid composite beam (HCB) used.

Table 1. Mechanical properties of the hybrid composite beam (HCB).

\begin{tabular}{ccccc}
\hline System & $\begin{array}{c}\text { Cross Section } \\
\left(\mathbf{m m}^{\mathbf{2}}\right)\end{array}$ & $\begin{array}{c}\text { Tensile Strength } \\
\mathbf{( M P a )}\end{array}$ & $\begin{array}{c}\text { Compressive Elastic } \\
\text { Modulus (GPa) }\end{array}$ & $\begin{array}{c}\text { Ultimate } \\
\text { Elongation (\%) }\end{array}$ \\
\hline Hybrid Composite beam & 1312 & 418 & 35.75 & 2.1 \\
\hline
\end{tabular}

\subsection{Specimens}

A total of five RC beams of $400 \mathrm{~mm}$ (width) $\times 600 \mathrm{~mm}$ (depth) $\times 6000 \mathrm{~mm}$ (length) were fabricated with an average concrete compressive strength of $22.8 \mathrm{MPa}$ at 28 days. The average concrete compressive strength was obtained from the four standard cylinders (100 $\mathrm{mm} \times 200 \mathrm{~mm}$ ). The beam dimensions of the RC used were chosen based on the typical full scale of school buildings in South Korea. According to design guidelines, each RC beam had five and two HD (high density) $19 \mathrm{~mm}$ bars for tension and compression reinforcement, respectively. Details of RC beam reinforcement are given in Figure 2. All steel bars used in the RC beam have a yield strength of approximately $480 \mathrm{MPa}$. Before bonding the hybrid composite beam, the tension surface of the RC beam was first sandblasted, cleaned and dried, and the epoxy was uniformly applied, and then externally bonded. To improve the bond between the hybrid composite beam and the concrete, commercially available power pins were uniformly used in the lips of the hybrid composite beams along with span length. The external bonding of the hybrid composite beams along a length of $5400 \mathrm{~mm}$ was undertaken in accordance with the requirements of the manufacturer of the hybrid composite system. All the strengthened RC beams were tested approximately 10 months after casting, and 3 months after externally bonded with hybrid composite beam. 

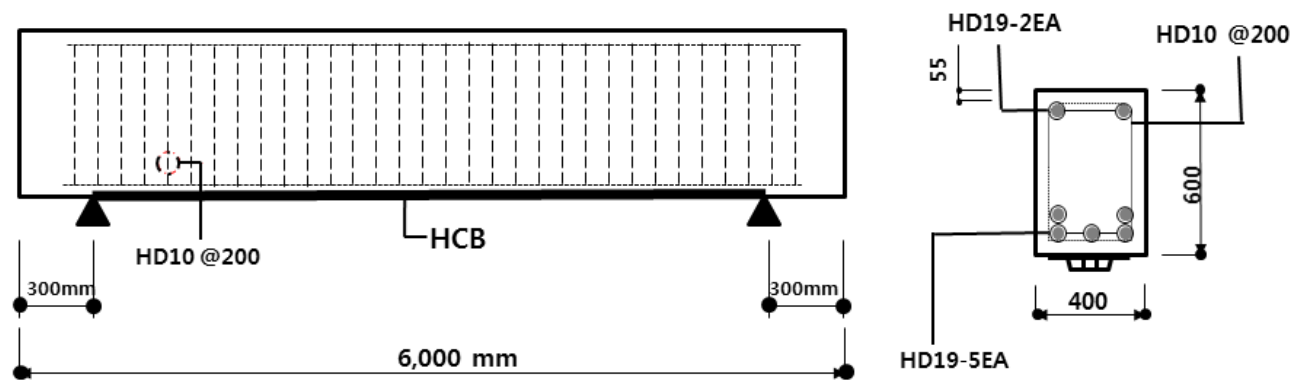

Figure 2. Details of the HCB-strengthened reinforced concrete (RC) beam specimen.

\subsection{Loading and Test Setup}

Prior to long-term tests, a short-term test was first conducted on an RC beam of $5400 \mathrm{~mm}$ clear span without strengthening to determine its ultimate load capacity, as shown in Figure 3. The test was conducted using a monotonic compressive loading at $500 \mathrm{kN}$ of the Material Testing System (MTS, Eden Prairie, MN, USA) with a maximum stroke of $150 \mathrm{~mm}$ [18]. The load was applied at the center of the specimen at a rate of $2.0 \mathrm{~mm} / \mathrm{min}$ up to ultimate failure. From the test, the first cracks at the bottom of the mid-span were observed about $70 \mathrm{kN}$, and then it moved up to half of the beam depth at about $110 \mathrm{kN}$. The obtained ultimate load from the short-term test without strengthening of the HCB was approximately $250 \mathrm{kN}$ with the maximum mid-span deflection of $24 \mathrm{~mm}$.

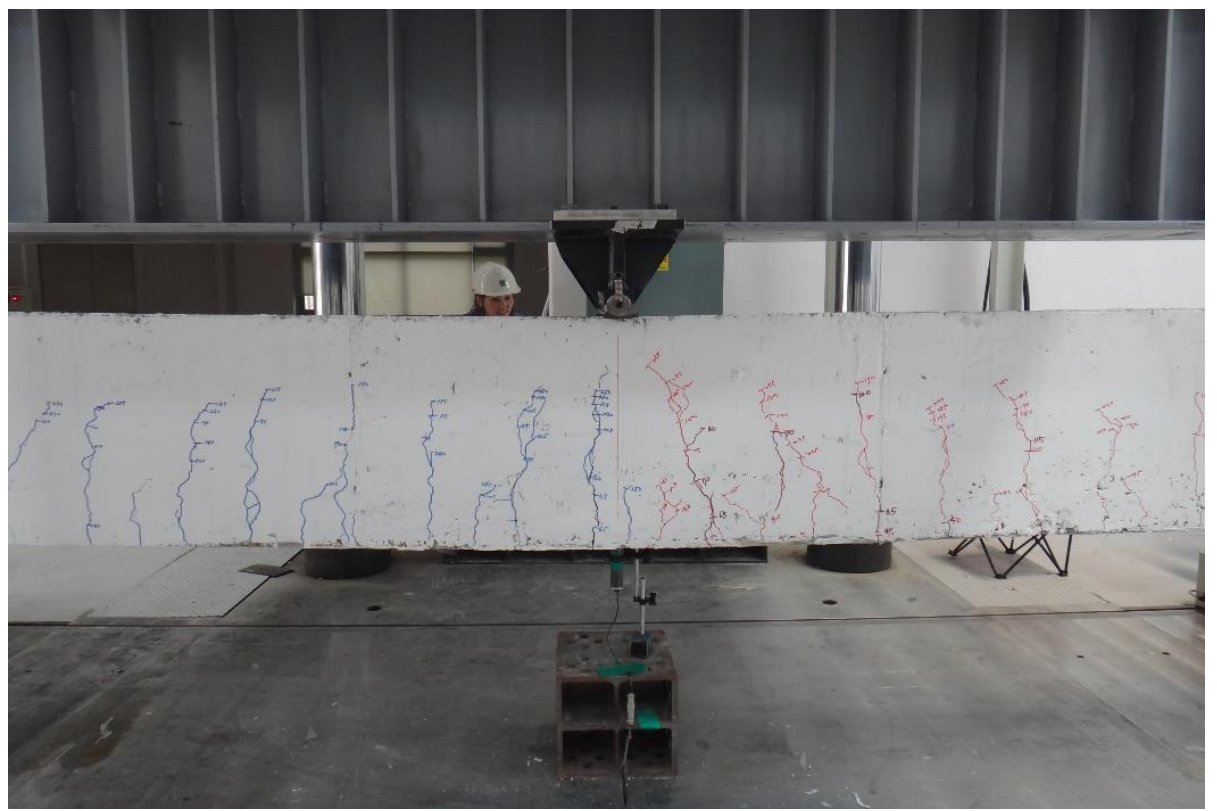

Figure 3. The short-term test on the reinforced concrete $(\mathrm{RC})$ beam specimen.

For the long-term test, two sustained loading levels from the results of the short-term test were considered on $\mathrm{RC}$ beams with and without strengthening of $\mathrm{HCB}$, in the present work. These loading levels are approximately $33 \%$ and $50 \%$ of the ultimate load capacity from the short-term test. It was assumed that these loading levels of $33 \%$ and $50 \%$ were enough within the line-elastic range. For the $33 \%$ loading level, a set of two RC beams with and without strengthening of a hybrid composite beam, was tested. For the 50\% loading level, one RC beam without strengthening of HCB and two RC beams with strengthening of HCB were tested. Figure 4 shows one of the long-term tests with the concrete loading mass. 


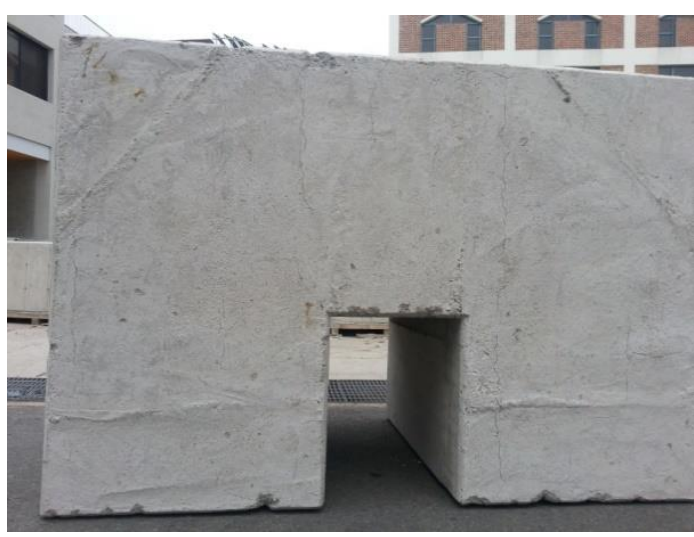

(a)

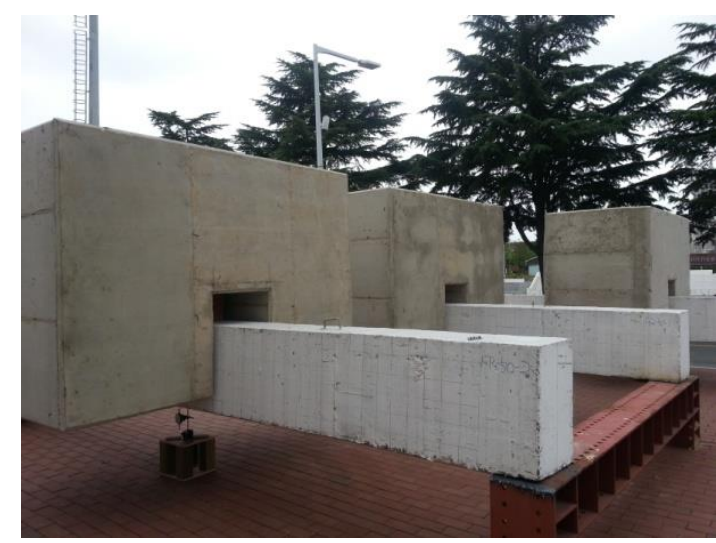

(b)

Figure 4. Long-term test setup: (a) loading mass; (b) test setup.

\subsection{Long-Term Measurement}

To measure the long-term deflection, a dial gauge was installed at the bottom of the mid-span for each HCB-strengthened or unstrengthened RC beam, as shown in Figure 5. Also, a multi-position strain gauge with a dial indicator reading of $0.0025 \mathrm{~mm}$ was used to measure the longitudinal tension strains of RC beams under the sustained loading. Two $254 \mathrm{~mm}$ gauge lines sustained by Demec gauges on each side of the RC beam were equally spaced at the center line, almost at the bottom of the beam section, as shown in Figure 5. The specimens were designed as follows: NHCB33 represents the non-strengthened hybrid composite RC beam subjected to a loading level of $33 \%$ of its ultimate beam capacity; HCB33 represents the HCB-strengthened RC beam subjected to a loading level of $33 \%$ of its ultimate beam capacity.

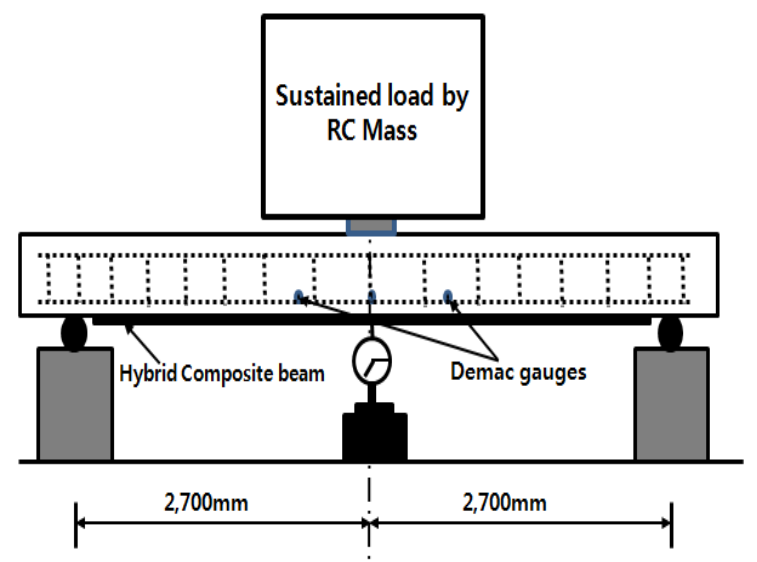

(a)

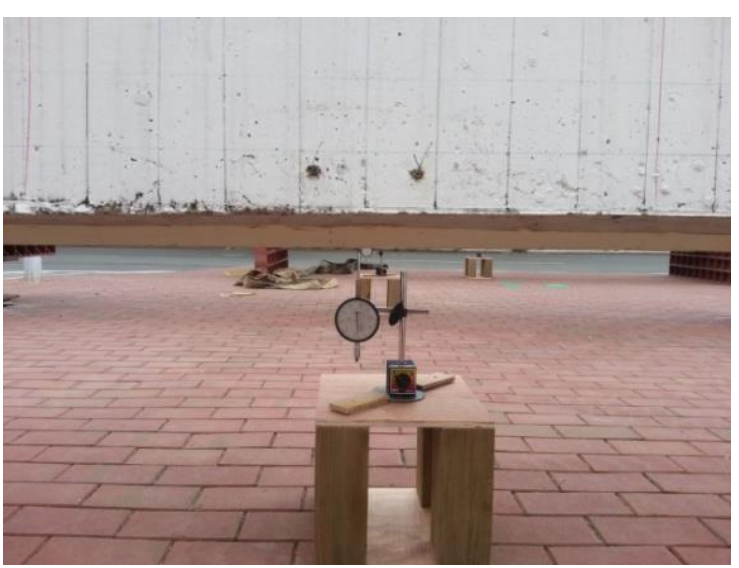

(b)

Figure 5. Schematic test setup and creep measurement: (a) schematic test setup; (b) measurement.

\subsection{Test Procedures}

The long-term tests in this work were carried out outside due to the size and difficulty of test setup with the normal weather conditions from June 2014 to June 2015 (almost 1 year). During testing, the specimens were subjected to average temperatures of $25.0{ }^{\circ} \mathrm{C}$ in summer (June-August), $15.5^{\circ} \mathrm{C}$ in autumn (September-November), $2.2^{\circ} \mathrm{C}$ in winter (December-February), and $13.7^{\circ} \mathrm{C}$ in spring (March-May), respectively. In this work, all RC beams with or without HCB strengthening, have been subjected to concentrated loading at the mid-span of the beams, and the time-dependent deflections were measured using a dial gauge. After loading, the deflections at mid-span and longitudinal beam tension strains were measured at the following time intervals [17]; 
Step 1: once every $10 \mathrm{~min}$ for the first hours.

Step 2: once every $1 \mathrm{~h}$ for the next $24 \mathrm{~h}$ following step 1.

Step 3: twice every day for the next 1 month following step 2.

Step 4: once every day for the next month.

Step 5: once every 7 days thereafter.

\section{Experimental Results and Discussions}

\subsection{Long-Term Deflection}

The measured instantaneous and long-term deflections for the unstrengthened and HCB-strengthened RC beams under the two different sustained loadings are summarized in Table 2. It was observed that the instantaneous deflections of HCB-strengthened RC beams are approximately $15 \%$ and 38\% lower than those of unstrengthened RC beams at 33\% and 50\% sustained loadings, respectively. Also, it was found that the long-term deflections of HCB-strengthened RC beams after 1 year were approximately $245 \%$ and $176 \%$ higher than those of the instantaneous deflection at $33 \%$ and $50 \%$ sustained loadings, while the long-term deflections of unstrengthened RC beams were approximately $278 \%$ and $152 \%$ higher than those of the instantaneous deflection at $33 \%$ and $50 \%$ sustained loadings, respectively. For more details, the time-dependent deflections of the HCB-strengthened RC beams at 1, 3, 6 and 12 months were approximately $24 \%, 14 \%, 22 \%$ and $25 \%$ lower than those of the unstrengthened RC beams under 33\% loading level, respectively. The time-dependent deflections of the HCB-strengthened RC beams at 1, 3, 6 and 12 months were approximately 30\%, 29\%, 29\% and 28\% lower than those of the unstrengthened RC beams under 50\% loading level, respectively.

Table 2. Long-term deflections of RC beams strengthened with HCB.

\begin{tabular}{ccccc}
\hline Time (days) & NHCB $\mathbf{3 3}(\mathbf{m m})$ & HCB $\mathbf{3 3}(\mathbf{m m})$ & NHCB $\mathbf{5 0}(\mathbf{m m})$ & HCB $\mathbf{5 0}(\mathbf{m m})$ \\
\hline 0 & 5.14 & 4.35 & 16.15 & 10.05 \\
\hline 30 & 9.25 & 7.06 & 19.26 & 13.48 \\
\hline 90 & 10.69 & 9.19 & 21.08 & 15.07 \\
\hline 180 & 12.73 & 9.93 & 22.29 & 15.91 \\
\hline 360 & 14.32 & 10.77 & 24.54 & 17.72 \\
\hline
\end{tabular}

Therefore, it can be concluded that HCB strengthening of the RC beams not only reduced the instantaneous deflection but it was also effective in controlling the time-dependent deflection for the entire time. In this investigation, as expected, we found that both the instantaneous and long-term deflections of both unstrengthened and HCB-strengthened RC beams at a higher loading level were increased, and the influence of HCB strengthening on the long-term deflection of RC beams is roughly proportional to the level of applied sustained loading. Figure 6 presents the graphical curves of additional deflections at the mid-span, along with loading time. The additional deflections in this study were obtained by subtracting the instantaneous deflection from the total deflection at given specific times. At 33\% loading level, the additional deflections of HCB-strengthened RC beams were smaller than those of unstrengthened RC beams. However, the additional deflections of HCB-strengthened beams at 50\% loading level showed similar values to the unstrengthened RC beams. At a higher loading level, a further investigation is needed due to such an unexpected result from the findings of this study. 


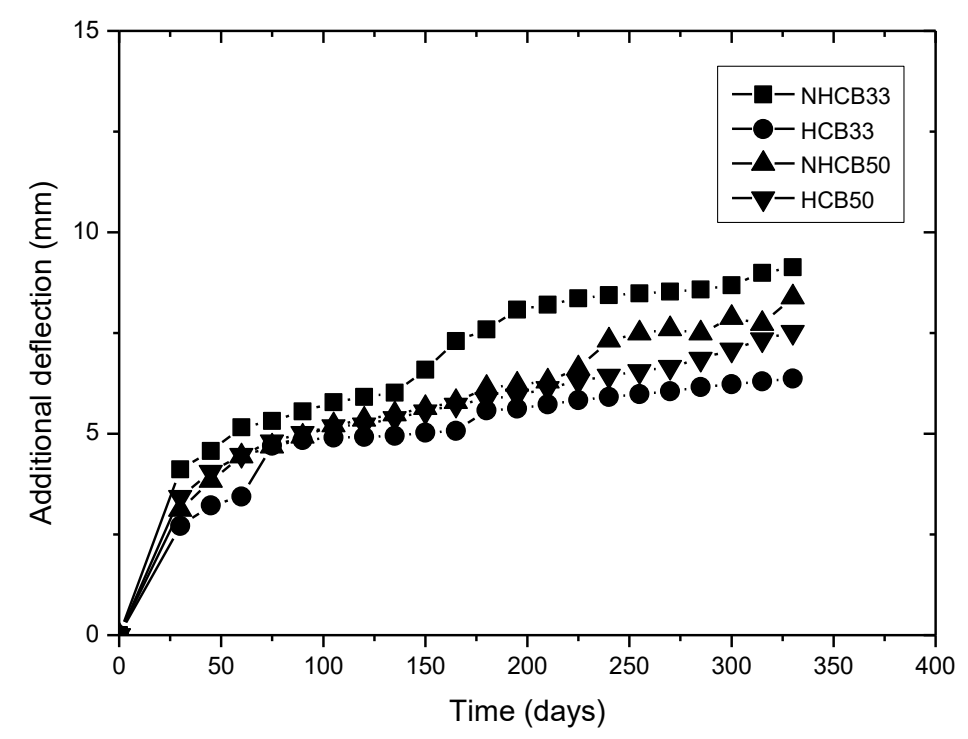

Figure 6. Additional deflections under two different sustained loadings.

Figure 7 shows the relationship between instantaneous deflection and the deflection of HCB-strengthened and unstrengthened RC beams. As seen in Figure 7, the ratios at a specific time of higher sustained loading level for unstrengthened and HCB-strengthened beams showed somewhat higher values than those of the relatively lower sustained loading level. This means that the strengthened and unstrengthened RC beams subjected to the higher sustained loading load level seemed to have no advantage for long-term deflection compared to lower sustained loading levels. This observation from this study was not clearly seen in other investigations.

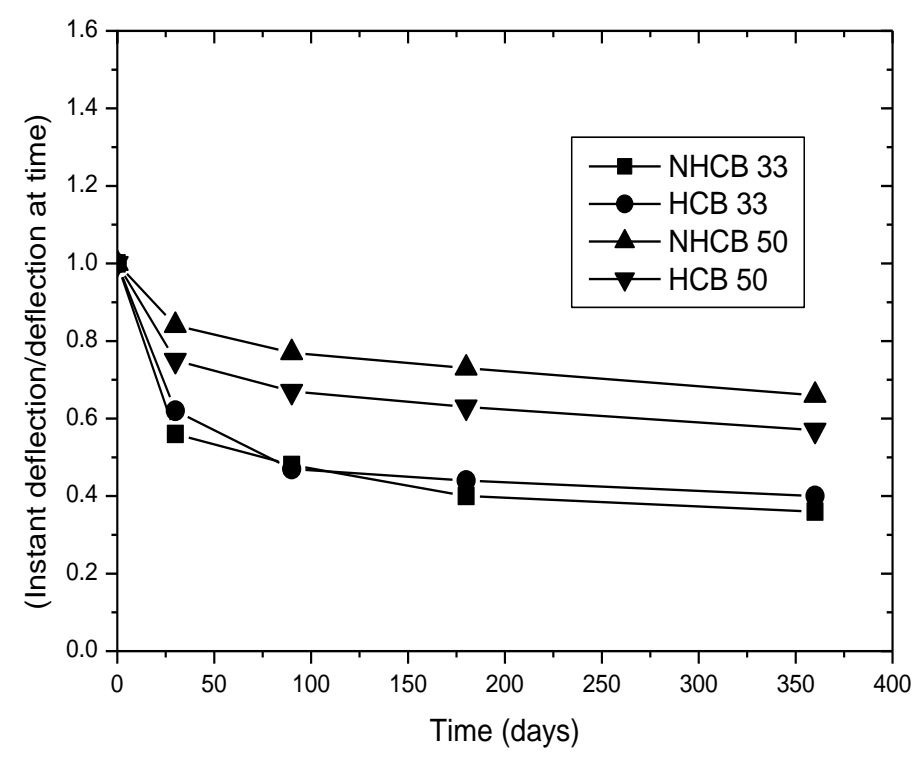

Figure 7. Variation of instantaneous deflection/deflection up to 1 year.

\subsection{Longitudinal Concrete Tensional Strains}

Figure 8 shows the average long-term longitudinal concrete tensional strains measured at both tension sides of the RC beams using Demec gauges. The observed concrete tensional strain of the HCB-strengthened RC beams at both loading levels yielded a slightly lower result than those of the unstrengthened RC beams. In this investigation, the instantaneous longitudinal concrete tensional strains of HCB-strengthened RC beams are approximately $3.62 \%$ and $2.56 \%$ lower than those of unstrengthened RC beams for loading levels of 33\% and 50\%, respectively. Also, it was 
observed that the long-term concrete strains of HCB-strengthened beams at 1 year were approximately $37.46 \%$ and $34.66 \%$ lower than those of unstrengthened beams at $33 \%$ and $50 \%$, respectively. For the HCB-strengthened RC beam, longitudinal concrete tensional strain testing found that approximately $28.45 \%$ and $26.96 \%$ of strains at 1 year occurred in the first $24 \mathrm{~h}$, and $35.80 \%$ and $34.56 \%$ strains occurred in the first 1 month for 33\% and 50\% loading levels, respectively. For the unstrengthened RC beams, longitudinal concrete tensional strain indicated that approximately $19.70 \%$ and $18.50 \%$ of strains at 1 year occurred in the first $24 \mathrm{~h}$, and $24.0 \%$ and $24.23 \%$ occurred in the first 1 month for $33 \%$ and $50 \%$ loading levels, respectively. Therefore, it can be concluded that RC beams strengthened by hybrid composite beams (HCB) were effective in controlling the longitudinal long-term concrete tensional strain under the given sustained loading levels.

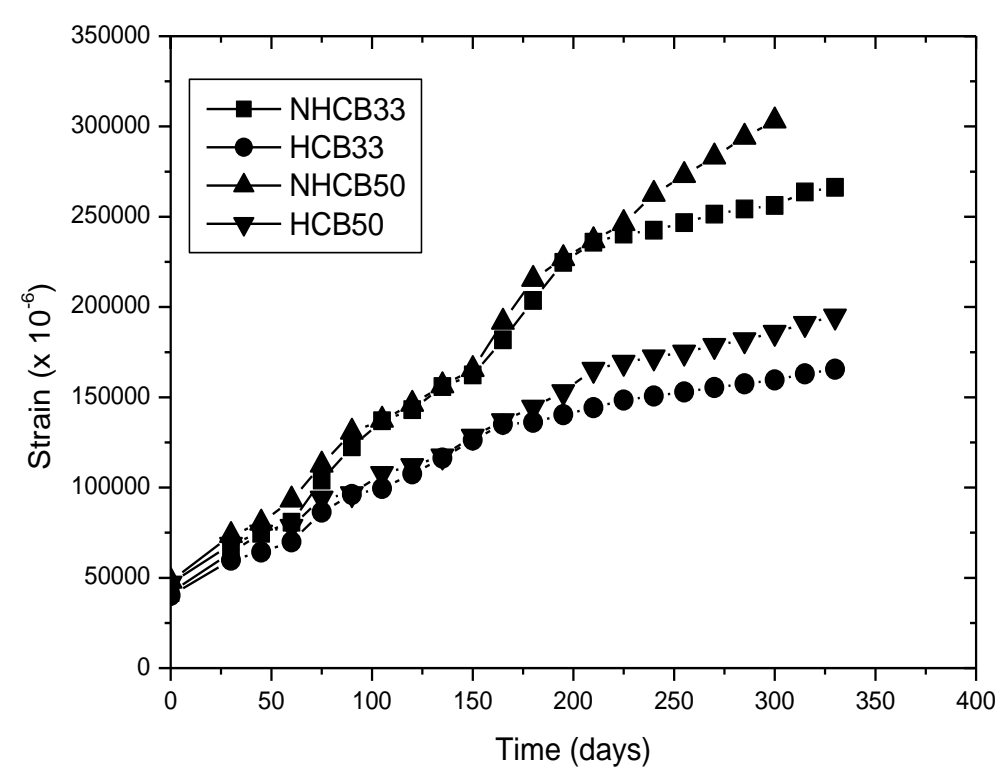

Figure 8. Longitudinal concrete tensional strains under sustained loading.

Figure 9 shows the percentage increase of longitudinal concrete tensional strains over the initial elastic strain. In this investigation, the percent increase of strain is calculated as follows:

$$
\varepsilon(\%)=\frac{\varepsilon(t)-\varepsilon(0)}{\varepsilon(0)} \times 100
$$

where $\varepsilon(\%)=$ the percentage increase of strain after time period $(t), \varepsilon(t)=$ the longitudinal concrete tensional strain measured from Demec gauges at the tension side of the RC beam at time $(t)$ and $\varepsilon(0)$ $=$ the initial longitudinal concrete tensional strain. 


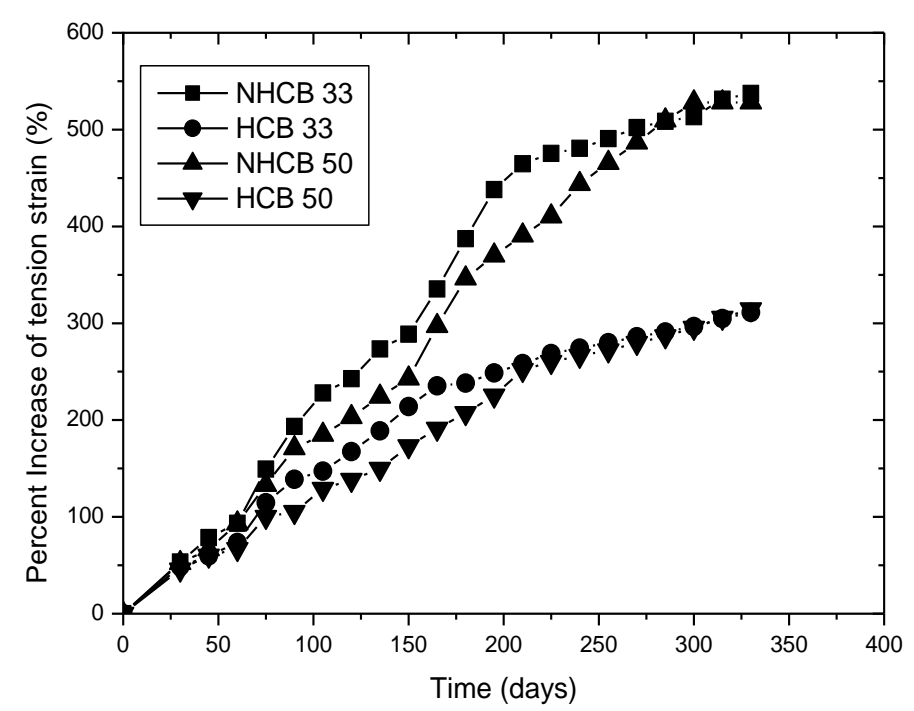

Figure 9. Percentage variation of longitudinal concrete tensional strains.

The percentage increase of concrete tensional strain was almost double at approximately 2 months for unstrengthened RC beams, and half a month for HCB-strengthened RC beams, respectively. Also, the percentage increase of concrete tensional strain of HCB-strengthened RC beams at 1 year was significantly lower than that of unstrengthened RC beams for both the loading levels.

\subsection{Evaluation of Time-Dependent Factors}

In this study, time-dependent factors of HCB-strengthened RC beams were investigated to understand the influence of external strengthening of HCB on RC beams. To determine the time-dependent factor from the long-term test, the well-known equation suggested by ACI 318 was adopted. This equation derived the additional long-term deflection resulting from creep and shrinkage of steel-reinforced concrete beams in terms of multiplying the instantaneous deflection by a factor. Therefore, it was assumed that the additional deflection of HCB-strengthened RC beams would be affected by the HCB strengthening, and the ACI equation would provide a somewhat adequate approximation in this study. The modified additional long-term deflection $\left(\triangle_{A D D}\right)$ of HCB-strengthened $\mathrm{RC}$ beams in this study may be written as

$$
\Delta_{A D D}=\frac{\xi}{1+50 S \rho^{\prime}}
$$

where, $\xi=$ time-dependent factor for sustained loading level, $s=$ flexural stiffness ratio between HCB-strengthened and unstrengthened RC beams $\left(\left(E I_{\text {beam }}+E I_{H C B}\right) /\left(E I_{\text {beam }}\right)\right)$ and $\rho^{\prime}=$ compression reinforcement ratio of steel bars in the RC beam section. The time-dependent factors found in this study using Equation (2) may be compared with the values found by Chami [10] and Arockiasamy [11] with similar FRP systems and ACI equations [9]. It should be noted that the ACI equation was proposed by steel reinforced concrete beams, while the values of Chami's study were obtained from RC beams with externally bonded CFRP laminates, and the values of Arockiasamy's study were obtained from CFRP bars reinforced with concrete beams. Table 3 presents the time-dependent factors from the present work with each of the different investigations up to 1 year. 
Table 3. Obtained time-dependent factors with other investigations

\begin{tabular}{ccccccccc}
\hline \multirow{2}{*}{ Load Time (month) } & \multicolumn{5}{c}{ Present Work } & \multirow{2}{*}{ ACI(2002) [9] } & Chami [10] & \multirow{2}{*}{ Arockiasamy [11] } \\
\cline { 2 - 6 } & NHCB33 & HCB33 & NHCB50 & HCB50 & & & \\
\hline 1 & 0.90 & 0.70 & 0.22 & 0.386 & 0.50 & 0.40 & - \\
\hline 3 & 1.22 & 1.25 & 0.34 & 0.565 & 1.00 & 0.60 & 0.70 \\
\hline 6 & 1.67 & 1.45 & 0.43 & 0.660 & 1.20 & 0.80 & 0.85 \\
\hline 9 & 1.87 & 1.57 & 0.53 & 0.750 & - & - & 1.15 \\
\hline 12 & 2.01 & 1.668 & 0.59 & 0.848 & 1.40 & 1.00 & - \\
\hline
\end{tabular}

In this investigation, we found that the time-dependent factors of HCB50 were approximately similar to those determined by Chami within 1 year. However, the time-dependent factors of HCB33 differed from those obtained by Chami by as much as $50 \%$. The average time-dependent factors of HCB33 were approximately 50\% higher than those of Arockiasamy, while HCB50 values were approximately 30\% lower than those of Arockiasamy. Given that the present work and the studies of Chami and Arockiasamy were performed using different strengthening materials, types and loading levels, it can be concluded that the time-dependent factor of FRP-strengthened RC beams is strongly dependent upon the type of FRP materials, strengthening method and sustained loading levels. The time-dependent factors of HCB-strengthened RC beams found in this study may also be compared with those values recommended by ACI. The time-dependent factors of HCB33 were on average $26.5 \%$ higher than those of ACI, while those of HCB50 were on average $38 \%$ lower than those of ACI. In the present work, the $\mathrm{ACI}$ equation may not provide a reasonable estimation of the long-term deflection behavior of HCB-strengthened RC beams. For unstrengthened RC beams at the two different loading levels, it was found that the time-dependent factors suggested by ACI ranged from, on average, $60 \%$ higher than NHCB50 to $45 \%$ lower than NHCB33. Actually, values of time-dependent factors of ACI are derived without a specifically applied sustained loading level. Based on the results of the present work, we suggested that the sustained loading level should not exceed $50 \%$ to ensure that the ACI equation can model the time-dependent factor of RC beams. Therefore, further tests with various conditions are needed to verify such a difference. The obtained time-dependent factors as a function of loading time are shown graphically in Figure 10 along with other investigations.

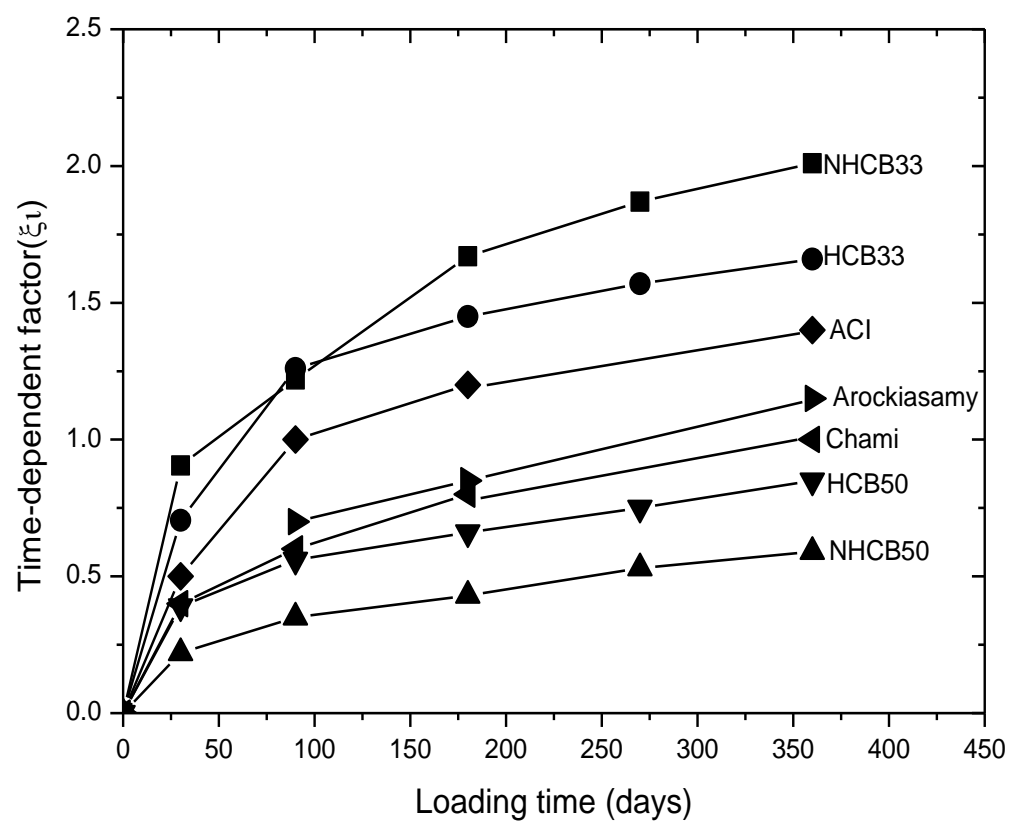

Figure 10. Time-independent factor $(\xi)$ under sustained loads. 


\section{Conclusions}

Based on the results of HCB-strengthened and unstrengthened RC beams at the two different sustained loading levels up to 1 year, the following conclusions are obtained:

(1) The long-term deflections of HCB-strengthened RC beams at the two different sustained loading levels of $33 \%$ and $50 \%$ at $1,3,6$ and 12 months were, on average, $27 \%, 22 \%, 25 \%$ and $26 \%$ lower than those of unstrengthened RC beams, respectively. The reduction rate of long-term deflection under the higher loading level showed a slightly higher value than that of the lower loading level.

(2) The long-term longitudinal concrete tensional strains of HCB-strengthened RC beams at 1 year were approximately $37.46 \%$ and $34.66 \%$ lower than those of unstrengthened RC beams for loading levels of $33 \%$ and $50 \%$, respectively.

(3) Compared to other investigations, the time-dependent factors of HCB-strengthened RC beams found in the present work differ from those in other investigations such as ACI, Chami and Arockiasamy. At the present time, we concluded that the time-dependent factors of FRP-strengthened RC beams are strongly dependent upon the strengthening types, materials, sustained loading levels, etc. Also, the time-dependent factor suggested by ACI for steel-reinforced concrete beams ( $\mathrm{RC}$ beams) does not reasonably predict the $\mathrm{RC}$ beam strengthened with various FRP materials.

Author Contributions: Y.C. and H.-J.L. conceived and designed the experiments; I.-H.K. and H.-J.L. performed the experiments; J.-W.K. and Y.C. analyzed the data; Y.C. and I.-H.K. wrote the paper.

Acknowledgments: The work presented in this paper was funded by the National Research Foundation of Korea (NRF-2014R1A2A2A01004164) under the Ministry of Science, ICT and Future Planning.

Conflicts of Interest: The authors declare no conflict of interest.

\section{References}

1. Toutanji, H.A.; Gomez, W. Durability characteristics of concrete beams externally bonded with FRP composite sheets. Cem. Concr. Compos. 1997, 19, 352-358. [CrossRef]

2. Rodriguez, M.; Park, R. Repair and strengthening of reinforced concrete buildings for seismic resistance. Earthquake Spectra 1991, 7, 439-450. [CrossRef]

3. Attart, N.; Amziane, S.; Chemrouk, M. Flexural strengthening of concrete beams using CFRP, GFRP and hybrid FRP sheets. Constr. Build. Mater. 2012, 26, 746-757. [CrossRef]

4. Balsamo, A.; Nardone, F.; Iovinella, I.; Ceroni, F.; Pecce, M. Flexural strengthening of concrete beams with EB-FRP, SRP and SRCM: Experimental investigation. Composites Part B 2013, 46, 91-101. [CrossRef]

5. Choi, Y.; Yuan, R.L. Time-dependent deformation of pultruded fiber reinforced polymer composite columns. J. Compos. Constr. 2003, 7, 356-362. [CrossRef]

6. Shim, J.-j.; Oh, K.-j.; Kim, Y.-t.; Park, S.-k. An experimental study on the behavior of RC beams externally bonded with FRPs under sustained loads. J. Korea Inst. Struct Maintenance Inspection 2014, 18, 167-177.

7. Hashemi, S.; Al-Mahaidi, R. Experimental and finite element analysis of flexural behavior of FRP-strengthened RC beams using cement-based adhesives. Constr. Build. Mater. 2012, 26, 268-273. [CrossRef]

8. Dai, J.G.; Ueda, T.; Sato, Y.; Ito, T. Flexural strengthening of RC beams using externally bonded FRP sheets through flexural adhesive bonding. In International Symposium on Bond Behavior of FRP in Structures (BBFS 2005); International Institute for FRP in Construction: Winnipeg, MB, Canada, 2005; pp. 205-213.

9. American Concrete Institute-Committee 440 (ACI440). Guide for the Design and Construction of Externally Bonded FRP Systems for Strengthening Concrete Structures; ACI 440.2R-02: Farmington Hills, MI, USA, 2002.

10. Chami, G.A.; Theriault, M.; Neale, K.W. Creep behavior of CFRP-strengthened reinforced concrete beams. Constr. Build. Mater. 2009, 23, 1640-1652. [CrossRef]

11. Arockiasamy, M.; Chidambaram, S.; Amer, A.; Shahawy, M. Time-dependent deformations of concrete beams reinforced with CFRP. Composites Part B 2000, 31, 577-592. [CrossRef]

12. Habibur, R.S.; Ehsan, A.; Norsuzailina, M.S. Deflection and cracking behavior of RC beams externally reinforced with carbon fiber liminates. J. Reinf. Plast. Compos. 2011, 30, 1807-1818. 
13. Diab, M.H.; Wu, Z.; Ahmed, E. Long-term deflections of beams strengthened by restressed and non-prestressed frp sheets. Int. J. Eng. Innovative Technol. 2013, 3, 108-114.

14. Mykolas, D.; Juozas, V.; Gediminas, M. Deflection analysis of reinforced concrete beams strengthened with carbon fiber reinforced polymer under long-term load action. J. Zhejiang Univ. Sci. 2012, 13, 571-583.

15. Gamata, G.; Spacone, E.; Zarnic, R. Experimental and nonlinear finite element studies of RC beams strengthened with FRP plates. Composites part B 2007, 38, 277-288.

16. Hosny, A.; Shaheen, H.; Abdelrahman, A.; Elafandy, T. performance of reinforced concrete beams strengthened by hybrid FRP laminates. Cem. Concr. Compos. 2006, 28, 906-913. [CrossRef]

17. Lee, H.-j. Long-Term Behavior of GFRP-Composite-Material Strengthened RC beams. Ph.D Thesis, School of Architecture and Civil Engineering, Kyungpook National University, Daegu, Korea, February 2016.

18. Park, I.-H.; Lee, H.-J.; Byeon, S.-M.; Choi, Y. Long-term brhavior of RC beams strengthened by GFRP composite beam. J. Regional Assoc. Architect. Inst. Korea 2017, 19, 79-86.

(C) 2019 by the authors. Licensee MDPI, Basel, Switzerland. This article is an open access article distributed under the terms and conditions of the Creative Commons Attribution (CC BY) license (http://creativecommons.org/licenses/by/4.0/). 